\title{
Relationship between insulin, glucose, non-esterified fatty acid and indices of insulin resistance in obese cows during the dry period and early lactation
}

\author{
Maja Došenović Marinković ${ }^{1}$, Branislava Belić ${ }^{1}$, Marko R. Cincović ${ }^{1}$, Radojica Đoković2 \\ Ivana Lakić ${ }^{1}$, Nenad Stojanac ${ }^{1}$, Ognjen Stevančević ${ }^{1}$, Gordana Devečerski ${ }^{3}$ \\ ${ }^{1}$ University of Novi Sad, Faculty of Agriculture, Department of Veterinary Medicine, \\ Laboratory of Pathophysiology, Novi Sad, Serbia \\ ${ }^{2}$ University of Kragujevac, Faculty of Agronomy, Department of Animal Science, \\ Čačak, Serbia \\ ${ }^{3}$ University of Novi Sad, Faculty of Medicine, Novi Sad, Serbia \\ Received February 18, 2018 \\ Accepted April 23, 2019
}

\begin{abstract}
The aim of this study was to determine to relationship between glucose, insulin, non-esterified fatty acid (NEFA) and indices of insulin resistance in the dry period (DP) and early lactation (EL). The importance of this study was in determining the relation between insulin sensitivity in DP and insulin resistance in EL. A total of 30 normally fed Holstein-Friesian cows with a high body condition score $(>3.75)$ were included in the study. Blood samples were collected in DP (weeks 5-7 ante partum) and EL (weeks 1-2 post partum). Cows in EL showed higher insulin resistance in comparison to DP due to a lower concentration of glucose and insulin, higher concentration of NEFA, lower value of revised quantitative insulin sensitivity check index and higher values of glucose:insulin and NEFA:insulin ratios (lower pancreas responsivnes to glucose and antilipolytic effect of insulin). Higher concentrations of insulin and glucose in the DP lead to a decrease in their concentrations and an increase in glucose:insulin and NEFA:insulin ratios in the EL. The revised quantitative insulin sensitivity check index in DP negatively correlates with the same index in EL, while positively correlating with the NEFA and NEFA:insulin ratio in EL. The EL revised quantitative insulin sensitivity check index value was influenced by dynamic changes (DP minus EL) in the insulin, NEFA, and glucose concentrations. The relationship between the indicators shows that higher insulin sensitivity in the DP increases resistance in EL in normally fed obese dairy cows.
\end{abstract}

Insulin sensitivity, periparturient period, energy balance, cattle

The period of lactation greatly affects the energy balance and insulin resistance in dairy cows. Insulin sensitivity/resistance is the principal mechanism for adapting the carbohydrate and lipid metabolism to lactation by directing glucose to the mammary gland and using adipose tissue to meet the energy requirements (De Koster and Opsomer 2013). Insulin resistance involves a decrease in insulin responsiveness, i.e. pancreatic betacell function, and/or insulin sensitivity, i.e. glucose entry into tissues through the action of insulin (Hayirli 2006).

In an experiment involving the use of insulin tolerance tests during 670 days of lactation, insulin resistance in the adipose tissue was found to change with the advance of lactation, creating favourable conditions for body fat deposition (Marett et al. 2017). Insulin has been proven to exert a lipogenic effect (Baumgard et al. 2016), which can lead to an increase in body fat reserves. Substantial body fat reserves in the dry period (DP) predispose cows to a significant decrease in the body condition score (BCS) after calving, increasing the overall lipid mobilization (Šamanc et al. 2015; Chapel et al. 2017). Increased lipid mobilization affects the insulin-regulated metabolism of carbohydrates and lipids, and reduces food intake, which can further aggravate the state of negative energy balance in early lactation

Address for correspondence:

Branislava Belić

Department of Veterinary Medicine

Faculty of Agriculture

University of Novi Sad

Trg D. Obradovića 8, 21000 Novi Sad, Serbia

Phone: +381214853516

E-mail: drbbelic@gmail.com

http://actavet.vfu.cz/ 
(EL) and even compromise the health of cows (Janovick and Drackley 2010; Salin et al. 2012). In the close-up period, food intake restrictions reduce lipid mobilization and increase insulin sensitivity (Vailati-Riboni et al. 2017). A negative energy balance in EL is characterized by decreased glucose and insulin concentrations, and the heightened insulin resistance in adipose tissue resulting in lipolysis and elevated non-esterified fatty acid (NEFA) levels. In addition to the BCS, glucose and insulin concentrations increase from the peak of lactation to the DP, whereas the magnitude of insulin resistance and lipolysis decreases (Allen and Piantoni 2014). During EL, the glucose supply is for the most part used to meet the glucose requirements of milk production as the glucose transporters (GLUT) in the mammary gland are insulin-independent. Conversely, adipose tissue is insulin-dependent, and thus a decrease in insulin concentrations causes elevated NEFA concentrations necessary for the energy requirements of the organism (Duehlmeier et al. 2007; Zhao and Keating 2007; Baumgard and Rhoads 2013).

The aim of this study was to examine whether the heightened insulin sensitivity expected in dairy cows amid the far-off DP leads to a compensatory increase in insulin resistance after parturition by analyzing the relationship between changes in the insulin, glucose, NEFA and Revised Quantitative Insulin Sensitivity Check Index (RQUICKI) values in the DP and EL.

\section{Materials and Methods}

\section{Cows and management}

A total of 30 Holstein-Friesian cows in the second and third lactation, with a milk yield of $7500 \pm 9501$ and no clinical signs of health impairment, were enrolled in the study. Raised in a free-range system, all the cows were amid the far-off DP (days $-40 \pm 7$ relative to calving) and with a BCS $>3.75$. They were fed total mixed rations (TMRs), adequately meeting the cows' nutritional requirements. The late-gestation cows received a diet of $1.5 \mathrm{~kg}$ grass hay, $0.60 \mathrm{~kg}$ wheat straw, $10 \mathrm{~kg}$ corn silage $(33 \%$ dry matter - DM), $2.50 \mathrm{~kg}$ alfalfa haylage $(51.79 \% \mathrm{DM}), 0.98 \mathrm{~kg}$ corn grain, $0.50 \mathrm{~kg}$ barley grain, $0.30 \mathrm{~kg}$ soybean grits, $1.10 \mathrm{~kg}$ soybean meal $(44 \% \mathrm{~N})$ and $0.50 \mathrm{~kg}$ wheat flour. The EL cows received a diet of $3.43 \mathrm{~kg}$ alfalfa hay, $9.50 \mathrm{~kg}$ corn silage (44\% DM), $9.0 \mathrm{~kg}$ corn silage $(33.94 \% \mathrm{DM}), 5.0 \mathrm{~kg}$ alfalfa haylage $(47.40 \% \mathrm{DM}), 5.0 \mathrm{~kg}$ brewer's grain $(21.0 \% \mathrm{DM}), 2.50$ $\mathrm{kg}$ corn grain, $1.50 \mathrm{~kg}$ barley grain, $1.30 \mathrm{~kg}$ soybean grits, $1.13 \mathrm{~kg}$ soybean meal $(44 \% \mathrm{~N}), 1.30 \mathrm{~kg}$ wheat flour and $1.82 \mathrm{~kg}$ sugar beet pulp.

\section{Blood sampling}

Blood samples were collected by coccygeal venipuncture before the morning feeding to minimize the postprandial effect on metabolic values. Blood samples were taken in weeks 5 to 7 ante partum (DP) and weeks 1 to 2 post partum (EL). The samples for biochemical analysis were collected in $10 \mathrm{ml}$ BD Vacutainer ${ }^{\circledR}$ SST II Advance tubes (BD Plymoth, UK), containing silica to activate the specimen clotting and a gel which forms a barrier between the clot and the serum after centrifugation. The collection tubes were centrifuged at $3,500 \times g$ for $10 \mathrm{~min}$ in order to completely separate the serum from the clot. The collected blood samples immediately underwent laboratory analysis.

\section{Blood sample analysis}

Concentrations of glucose, insulin and NEFA were determined in the blood samples collected during the DP. The glucose and NEFA levels were measured using the spectrophotometric Randox (Crumlin, UK) and Biosystems (Barcelona, Spain) kits, and the values obtained were read using a Rayto biochemistry analyzer. The insulin concentrations were determined using the Sandwich enzyme-linked immunosorbent assay (ELISA) kit Cusabio (Wuhan, China), and the insulin values were read using an ELISA reader Rayto (Shenzen, China).

\section{Calculation of the indices}

The testing for insulin resistance in this study was based on the RQUICKI index (RQUICKI $=1 /$ [ $\log ($ glucose $\mathrm{mg} / \mathrm{dl})+\log ($ insulin $\mu \mathrm{U} / \mathrm{ml})+\log (\mathrm{NEFA}$ mmol/l)] $)($ Holtenius and Holtenius 2007). The NEFA:insulin and glucose:insulin ratios were calculated as a unit of NEFA and glucose per one unit of insulin, representing the insulin response to the glucose and insulin antilipolytic effect.

\section{Data analysis}

Differences in the insulin, glucose, NEFA and RQUICKI values during the DP and EL were determined using paired $t$-tests. The relationship between the obtained values was examined using correlation and regression between the insulin, glucose, NEFA and RQUICKI values in the DP and the period after parturition. A multiple 
regression equation was used to explicate the effect of dynamic changes in the insulin, glucose and NEFA values on the RQUICKI values after parturition.

\section{Results}

CowsinELshowed higher insulin resistance in comparison to DP due to lowerconcentration of glucose and insulin, a higher concentration of NEFA, a lower value of RQUICKI and higher values of glucose:insulin and NEFA:insulin ratios (lower pancreas responsivnes to glucose and the antilipolytic effect of insulin). These values were determined in the DP vs EL: glucose $3.4 \pm 0.35$ vs $2.42 \pm 0.42 \mathrm{mmol} / \mathrm{l}$; insulin $17.27 \pm 3.02$ vs $10.48 \pm 2.33 \mu \mathrm{U} / \mathrm{l} ; \mathrm{NEFA}$ $0.19 \pm 0.08$ vs $0.6 \pm 0.18 \mathrm{mmol} / \mathrm{l}$; RQUICKI $0.44 \pm 0.02$ vs $0.41 \pm 0.03$; glucose:insulin ratio $3.67 \pm 0.76: 4.26 \pm 0.72$; and NEFA:insulin ratio $0.012 \pm 0.009: 0.061 \pm 0.03$. The results of paired $t$-tests indicate a significant difference between the values obtained in the DP and the EL (Table 1).

Higher insulin sensitivity in the DP increases resistance in the EL due to the following factors: a) higher concentrations of insulin and glucose in the DP lead to

Table 1. Differences in the values of glucose, insulin, non-esterified fatty acid (NEFA), revised quantitative insulin sensitivity check index (RQUICKI), and glucose:insulin and NEFA:insulin ratios in the dry period (DP) and early lactation (EL) using paired sample $t$-test.

\begin{tabular}{lcrc}
\hline & DP & \multicolumn{1}{c}{ EL } & $P$ (paired $t$-test) \\
\hline Insulin & $17.27 \pm 3.02$ & $10.48 \pm 2.33$ & $<0.001$ \\
Glucose & $3.41 \pm 0.35$ & $2.42 \pm 0.42$ & $<0.001$ \\
NEFA & $0.19 \pm 0.08$ & $0.6 \pm 0.18$ & $<0.001$ \\
RQUICKI & $0.44 \pm 0.02$ & $0.42 \pm 0.03$ & $<0.05$ \\
Glucose:insulin ratio & $3.67 \pm 0.76$ & $4.26 \pm 0.72$ & $<0.05$ \\
NEFA:insulin ratio & $0.012 \pm 0.009$ & $0.061 \pm 0.03$ & $<0.001$ \\
\hline
\end{tabular}

a decrease in the their concentrations and an increase in the glucose:insulin and NEFA:insulin ratios in the EL; b) the RQUICKI in the DP negatively correlates with the same index in the EL while positively correlating with the NEFA and NEFA:insulin ratio

in the EL. Correlations and regressions are presented at Table 2 and Figs 1a-d, 2a-d, 3a-d.

Table 2. Correlation and regression between indicators in the dry period (DP), early lactation (EL) and the dynamic change of indicators (delta, EL minus the DP value).

\begin{tabular}{llrr}
\hline Indicators & \multicolumn{1}{c}{ Equation } & R & $P$ \\
\hline Insulin DP to insulin EL & Insulin EL $=15.35-0.28 \times$ insulin DP & -0.45 & $<0.05$ \\
Glucose DP to glucose EL & Glucose EL $=2.3+0.03 \times$ glucose DP & $\sim 0$ & NS \\
NEFA DP to NEFA EL* & NEFA EL $=0.79-0.99 \times$ NEFA DP & -0.46 & $<0.05$ \\
RQUICKI DP to RQUICKI EL* & RQUICKI EL $=0.63-0.48 \times$ RQUICKI DP & -0.38 & $<0.05$ \\
Insulin DP to insulin delta & Insulin delta $=15.36-1.28 \times$ insulin DP & -0.87 & $<0.01$ \\
Glucose DP to glucose delta & Glucose delta $=2.3-0.97 \times$ glucose DP & -0.63 & $<0.01$ \\
NEFA DP to NEFA delta & NEFA delta $=0.8-2.01 \times$ NEFA DP & -0.71 & $<0.01$ \\
RQUICKI DP to RQUICKI delta & RQUICKI delta $=-0.62+1.45 \times$ RQUICKI DP & 0.79 & $<0.01$ \\
RQUICKI DP to NEFA EL & NEFA EL $=-1.39+4.54 \times$ RQUICKI DP & 0.58 & $<0.01$ \\
RQUICKI DP to NEFA:insulin EL & NEFA:insulin EL $=-0.12+0.42 \times$ RQUICKI DP & 0.37 & $<0.05$ \\
Insulin DP to glucose:insulin EL & Glucose:insulin EL $=2.53+0.1 \times$ insulin DP & 0.42 & $<0.05$ \\
Insulin DP to NEFA:insulin EL & NEFA:insulin EL $=0.003+0.003-3 \times$ insulin DP & 0.39 & $<0.05$ \\
\hline
\end{tabular}

*non-esterified fatty acid (NEFA), revised quantitative insulin sensitivity check index (RQUICKI) 

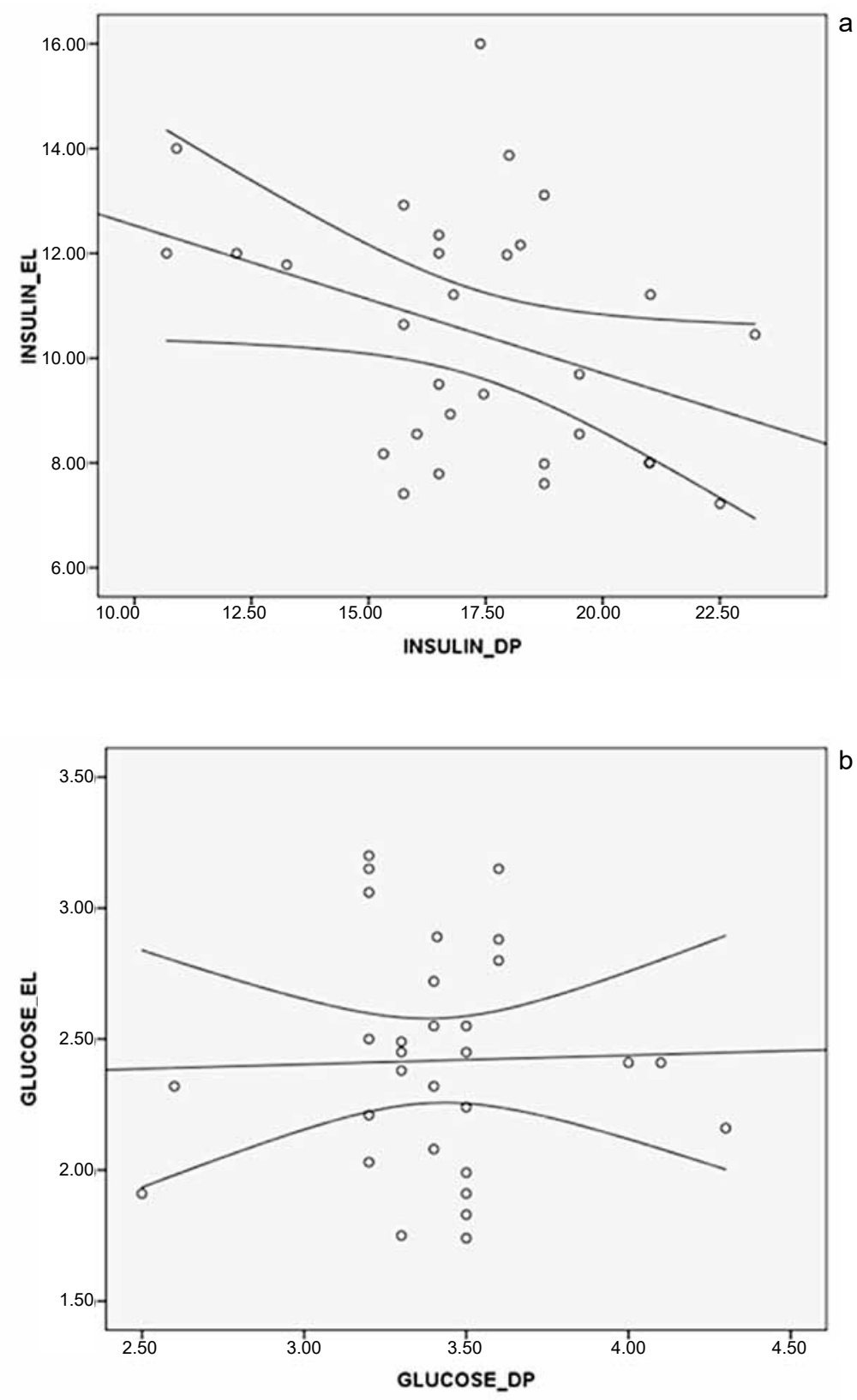

b Fig. 1a-d. Visualization of the regression line between insulin, glucose, non-esterified fatty acid (NEFA) and the revised quantitative insulin sensitivity check index (RQUICKI)in the dry period (DP) and early lactation (EL). 

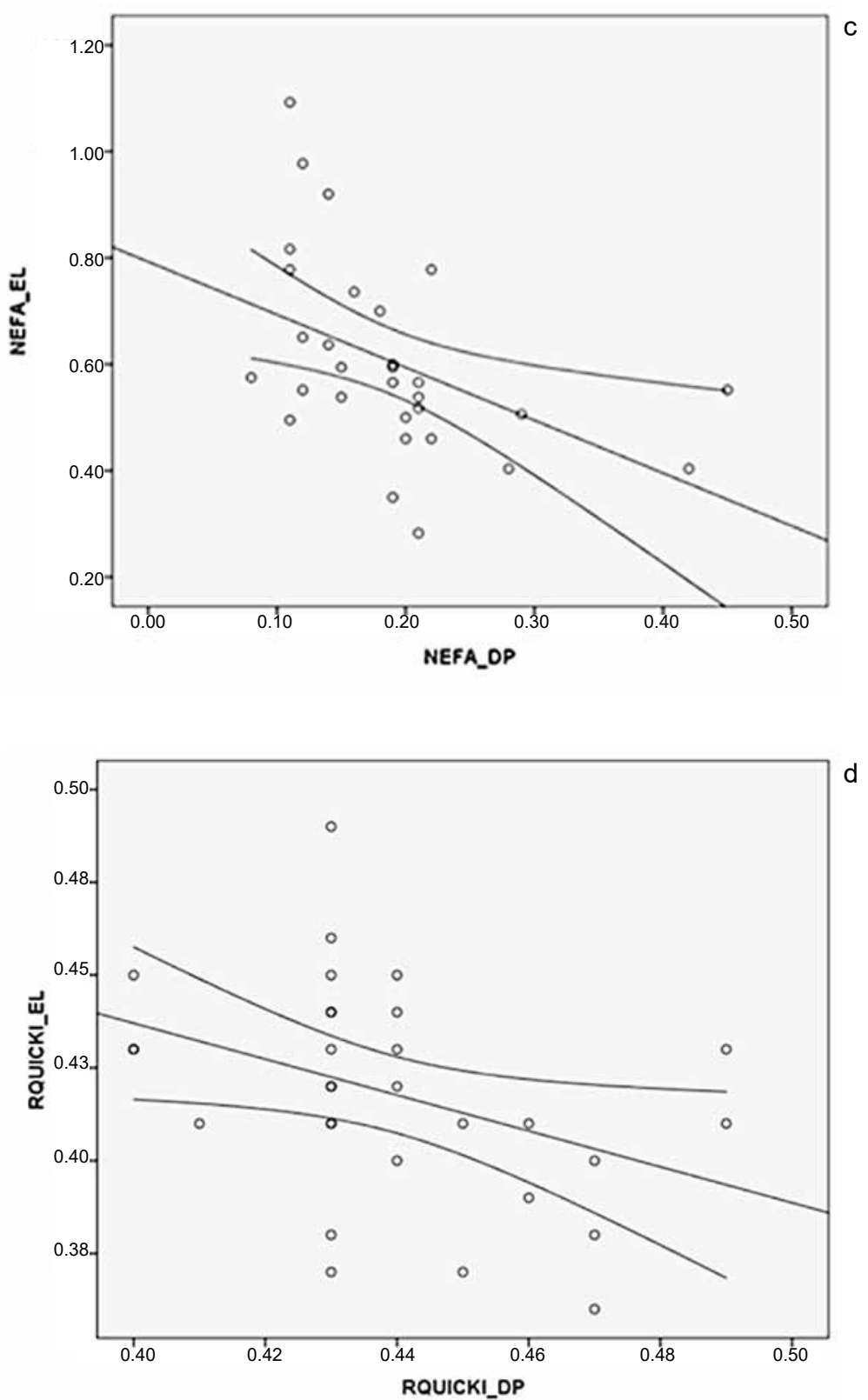

Fig. 1a-d. Visualization of the regression line between insulin, glucose, non-esterified fatty acid (NEFA) and the revised quantitative insulin sensitivity check index (RQUICKI)in the dry period (DP) and early lactation (EL). 

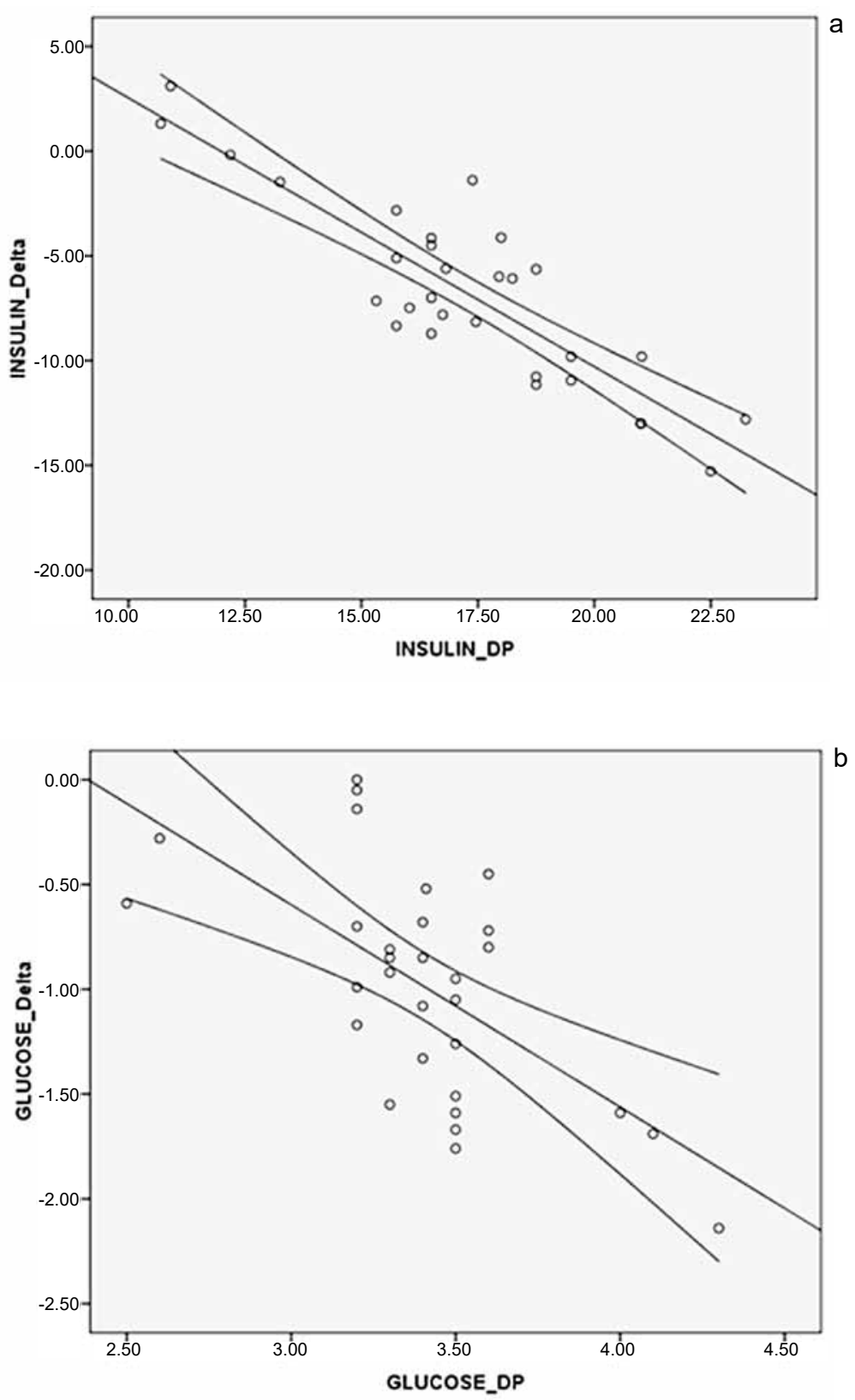

Fig. 2a-d.Visualization of the regression line between the dry period (DP) and the magnitude of change (delta) of insulin, glucose, non-esterified fatty acid (NEFA) and revised quantitative insulin sensitivity check index (RQUICKI) values. 

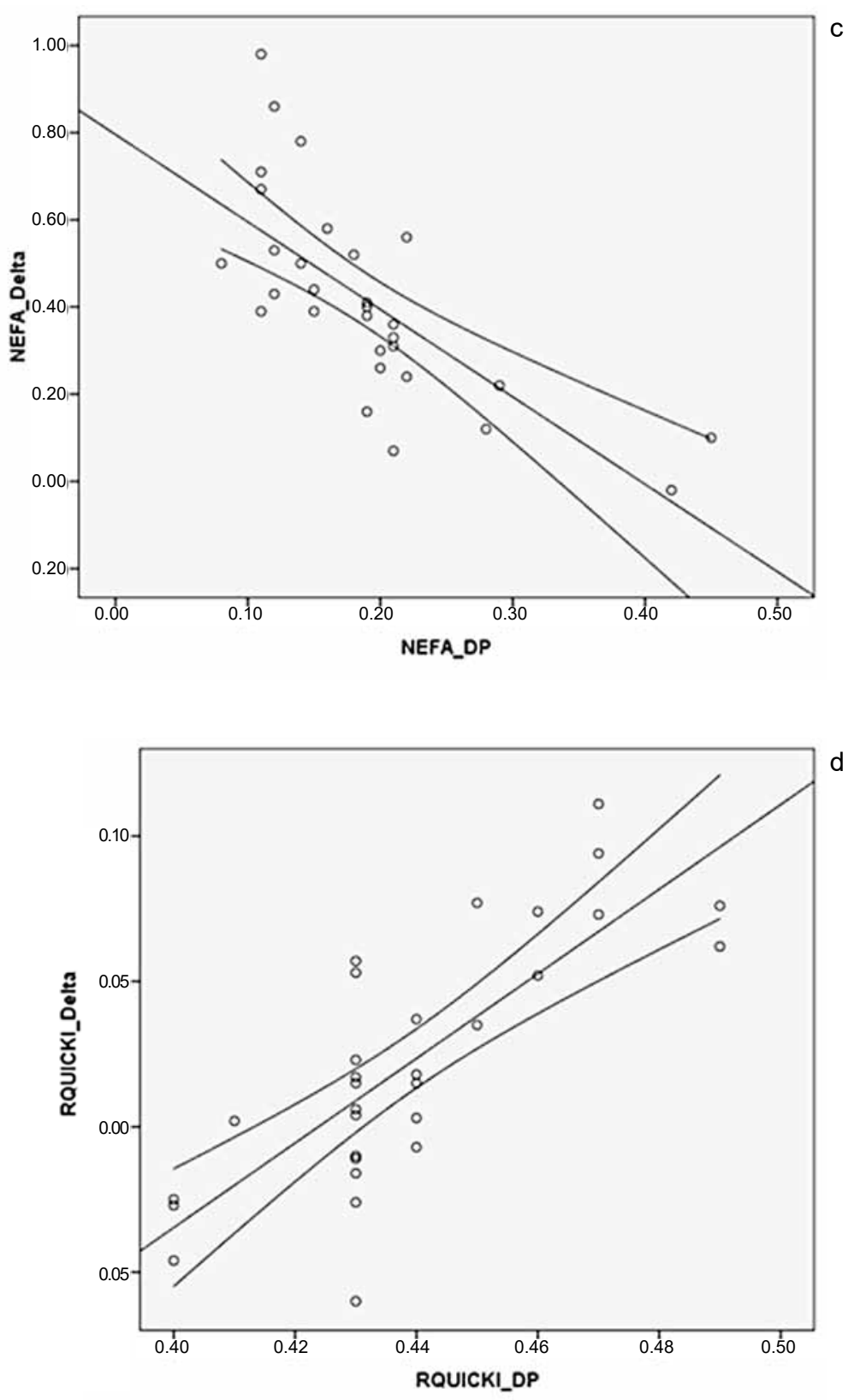

Fig. 2a-d.Visualization of the regression line between the dry period (DP) and the magnitude of change (delta) of insulin, glucose, non-esterified fatty acid (NEFA) and revised quantitative insulin sensitivity check index (RQUICKI) values. 

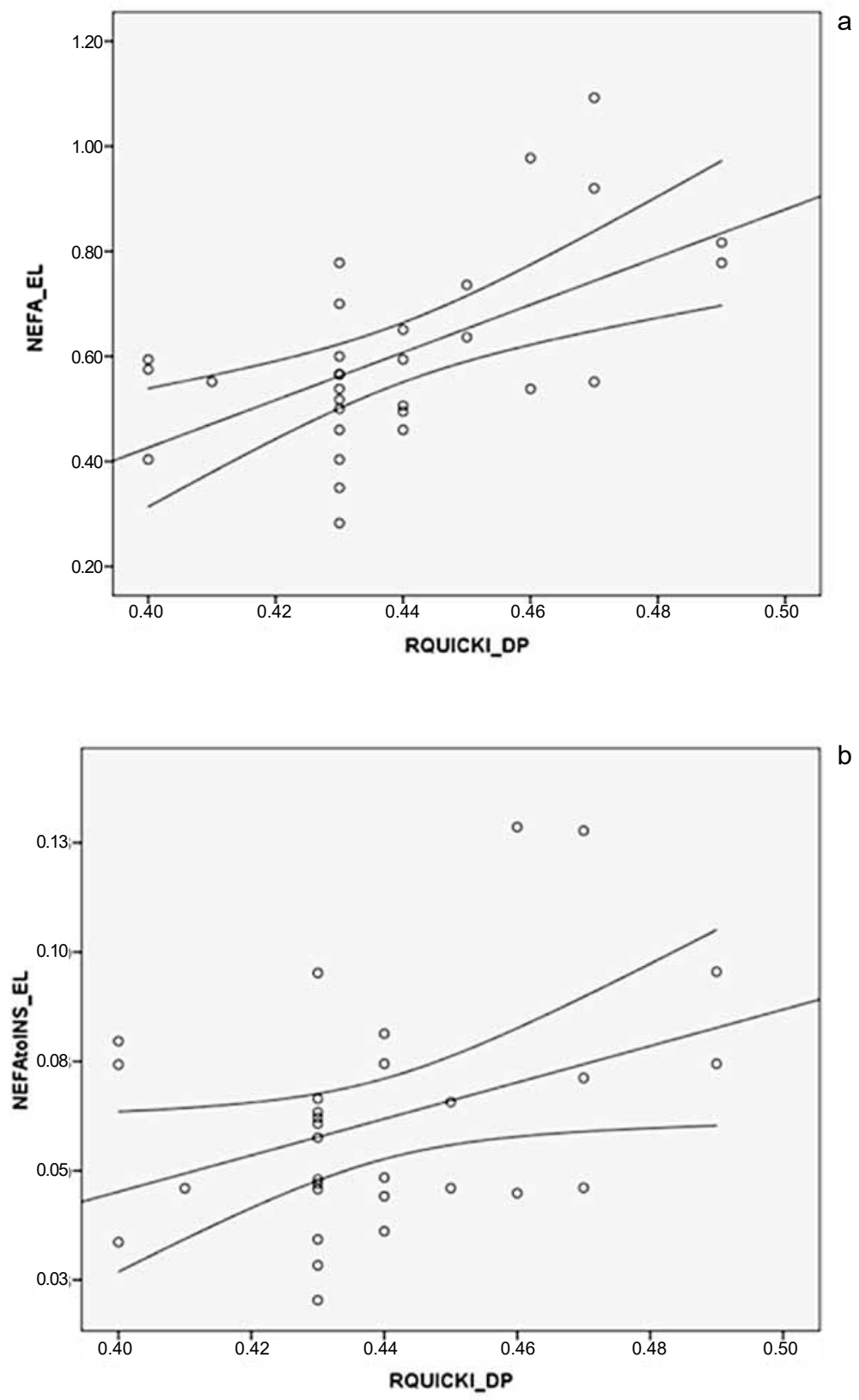

Fig. 3a-d.Visualization of the regression line between the revised quantitative insulin sensitivity check index in the dry period (RQUICKI_DP) with non-esterified fatty acid (NEFA) and the NEFA: insulin (NEFAtoINS) ratio in early lactation (EL); insulin in the dry period (Insulin_DP) with the NEFA:insulin and glucose:insulin (GLUtoINS) ratios in early lactation (EL). 

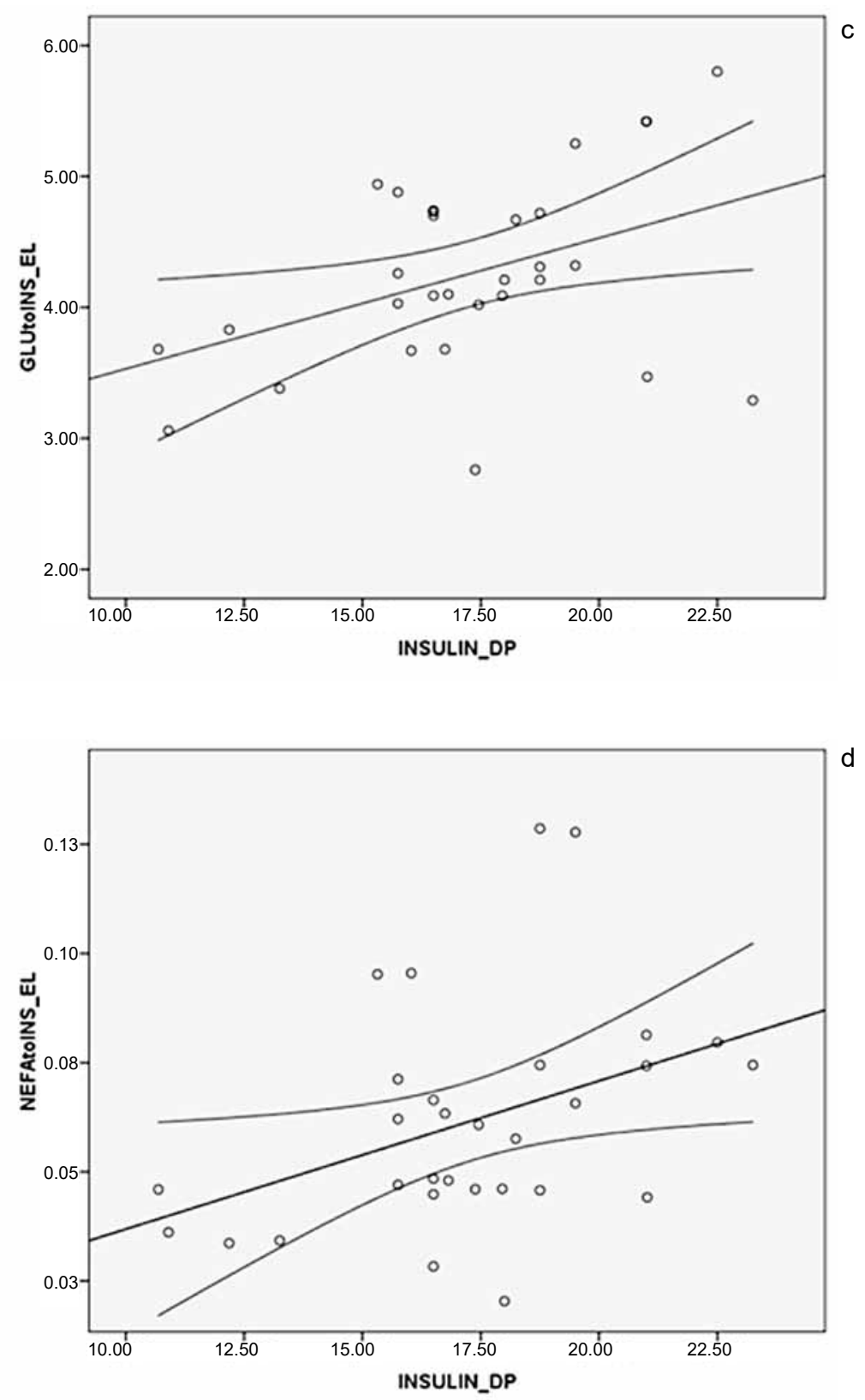

Fig. 3a-d. Visualization of the regression line between the revised quantitative insulin sensitivity check index in the dry period (RQUICKI_DP) with non-esterified fatty acid (NEFA) and the NEFA:insulin (NEFAtoINS) ratio in early lactation (EL); insulin in the dry period (Insulin_DP) with the NEFA:insulin and glucose:insulin (GLUtoINS) ratios in early lactation (EL). 
The RQUICKI value in the EL was influenced by dynamic changes (DP minus EL) of the insulin, NEFA, and glucose concentrations. The change in NEFA showed the highest contribution to the RQUICKI value (highest t-value). Results are presented at Table 3 and Fig. 4.

Table 3. The effect of the dynamic change (delta, magnitude of change between early lactation minus dry period value) of insulin, glucose and non-esterified fatty acid (NEFA) on the value of the revised quantitative insulin sensitivity check index in early lactation (RQUICKI EL) (RQUICKI EL $=\mathrm{a}+\mathrm{b} 1 \mathrm{INSULIN}$ Delta $+\mathrm{b} 2 \mathrm{GLUCOSE}$ Delta + b3 NEFA Delta + Error)

\begin{tabular}{|c|c|c|c|c|c|c|}
\hline \multirow{2}{*}{$\begin{array}{l}\text { Model } \\
\text { RQUICKI EL } \\
\text { independent value }\end{array}$} & \multicolumn{3}{|c|}{ Significance of indicators } & \multicolumn{3}{|c|}{ Significance of the whole model } \\
\hline & Beta & $t$ & $P$ & $\mathrm{R}\left(\mathrm{R}^{2} \%\right)$ & $\mathrm{F}$ & $P$ \\
\hline (Constant) & & 52.4 & $<0.001$ & & & \\
\hline INSULIN Delta & -0.606 & -4.8 & $<0.001$ & $0.85(72 \%)$ & 22.6 & $<0.001$ \\
\hline GLUCOSE Delta & -0.398 & -2.1 & $<0.05$ & & & \\
\hline NEFA Delta & -0.797 & -6.6 & $<0.001$ & & & \\
\hline
\end{tabular}

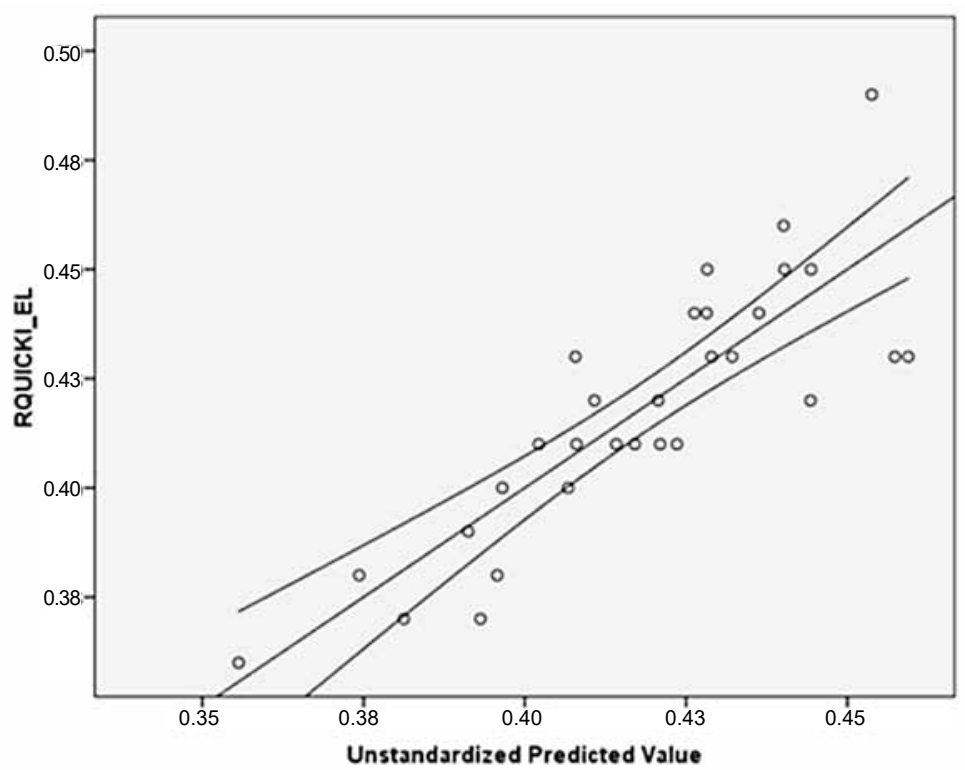

Fig. 4. Visualization of the multiple regression equation (RQUICKI EL $=a+b 1$ INSULIN Delta + b2 GLUCOSE Delta + b3 NEFA Delta + error) (delta - magnitude of change between early lactation minus the dry period value; NEFA - non-esterified fatty acid; RQUICKI EL - revised quantitative insulin sensitivity check index in early lactation)

\section{Discussion}

An inverse correlation was found between the values of insulin, glucose, NEFA and RQUICKI in the DP and EL. The obtained results can be accounted for by the metabolic status of cows in the DP and EL. In mid- and late lactation, the energy requirements of the cow's organism are fully met. Moreover, the energy supplies often exceed the requirements, 
and thereby the surplus of energy is stored in body depots in the form of glycogen, fat, and protein (Grummer 2008). A positive energy balance is characterized by increased hepatic gluconeogenesis, decreased peripheral glucose uptake, constant or reduced acetate use, moderate fatty acid mobilization from body depots, and increased fatty acid utilization in the peripheral tissues (Bell 1995). Low insulin concentrations after parturition, secreted by pancreatic beta-cells, are associated with the decreased expression of insulin-dependent GLUT-4 transporters. Accordingly, the glucose uptake in muscle and adipose tissues is diminished in order to supply insulin-independent tissues with glucose (mammary gland). Such results were reported by Duehlmeier et al. (2007) and Zhao and Keating (2007).

Elevated insulin concentrations are associated with a positive energy balance (Holtenius et al. 2003; De Ko ster et al. 2015). An increase in insulinaemia can result as a consequence of insulin resistance (Ahrén and Pacini 2004). However, our results show that the DP insulin:glucose and insulin:NEFA ratios are lower than those obtained in the postpartum EL period, which is indicative of enhanced insulin sensitivity. A significant decrease in the insulin and glucose concentrations was reported in EL, and a positive correlation was found between the insulin and glucose values after parturition. A decrease in feed intake in the periparturient period lowers glucose concentrations (Bjerre-Harpøth et al. 2012). Oral feed (glucose) intake acts as a much stronger stimulus to insulin secretion than intravenous glucose administration, as glucose regulates insulin gene expression (Baumagard et al. 2016). All the aforementioned considerations confirm a significant correlation between insulin and glucose values in the postpartum period.

A significantly negative correlation was found between insulin and NEFA values in the DP (Table 2) compared to the non-significant correlation found in the postpartum period. Elevated NEFA concentrations decrease glucose clearance due to lower insulin sensitivity in tissues, changes in insulin secretion and changes in insulin clearance (Salin et al. 2012; Schoenberg et al. 2012). A laboratory mouse model was used to show adverse effects of NEFAs on pancreatic beta-cells (Meadler et al. 2001). Pires et al. (2007) demonstrated a relationship between NEFA concentrations and insulin resistance in cows by induced hyperlipidaemia, infusing tallow emulsion.

The RQUICKI is an indirect indicator of insulin sensitivity in cows. This index shows lower values in EL compared to the DP (Cincović et al. 2014), and a significant relationship with the metabolic and endocrinological indicators in EL (Cincović et al. 2017). A negative correlation was found between the RQUICKI values and the insulin, glucose, and NEFA values in the EL period, compared to a significant correlation between the RQUICKI and NEFA values in the DP period. A negative correlation between the RQUICKI and insulin values was also found by Locher et al. (2015). The RQUICKI index is an excellent indicator of the antilipolytic effect of insulin (Perseghin et al. 2001). Models examining high energy intake during the DP have demonstrated a decrease in the index of insulin sensitivity and an increase in insulin values in overfed/overconditioned cows compared to normally-fed cows, and no differences were found in the postpartum insulin sensitivity (or that it was even enhanced) (Rukkwamsuk et al. 1998; Locher et al. 2015; Salin et al. 2017). The RQUICKI index can only be used for the assessment of insulin resistance in cows with the same metabolic status (Schoenberg and Overton 2011). Therefore, it is rather difficult to make a direct comparison of our results with those reported elsewhere in the literature.

The obtained postpartum RQUICKI values were influenced by dynamic changes in the insulin, glucose and NEFA values in the periparturient period. Significant changes were recorded in the insulin and NEFA values compared to the changes in glycaemia (the t-value comparison), which confirms that the RQUICKI index was indicative of the antilipolytic effect of insulin in this study. The correlation between the obtained values suggests that changes in insulin secretion and lipid levels greatly affect the 
insulin resistance in EL. The negative correlation determined between RQUICKI values in the DP and EL is influenced by the magnitude of change in lipolysis. Bossaert et al. (2008) reported a negative correlation between plasma NEFA values and the insulin area under the curve and peak values, without affecting the glucose values in postpartum cows.

In conclusion, the relationship between insulin, glucose, NEFA, RQUICKI, glucose to insulin and NEFA to insulin ratio in the DP and EL presented that higher insulin sensitivity in DP compensatory increases resistance in EL in normally-fed obese dairy cows. Analysis of the mentioned indicators during the DP in obese cows may be a practical tool for a prediction of insulin resistance in EL. These findings warrant further research.

\section{Acknowledgement}

This study was funded by the Ministry of Education, Science and Technology of the Republic of Serbia, under Project No. TR31062.

\section{References}

Ahrén B, Pacini G 2004: Importance of quantifying insulin secretion in relation to insulin sensitivity to accurately assess beta cell function in clinical studies. Eur J Endocrinol 150: 97-104

Allen MS, Piantoni P 2014: Carbohydrate nutrition-managing energy intake and partitioning through lactation. Vet Clin North Am Food Anim Pract 30: 577-597

Baumgard LH, Rhoads RP 2013: Effects of heat stress on postabsorptive metabolism and energetics. Annu Rev Anim Biosci 1: 311-337

Baumgard LH, Hausman GJ, Sanz Fernandez MV 2016: Insulin: pancreatic secretion and adipocyte regulation. Domest Anim Endocrinol 54: 76-84

Bell AW 1995: Regulation of organic nutrient metabolism during transition from late pregnancy to early lactation. J AnimSci 73: 2804-2819

Bjerre-Harpøth V, Friggens NC, Thorup VM, Larsen T, Damgaard BM, Ingvartsen KL, Moyes KM 2012: Metabolic and production profiles of dairy cows in response to decreased nutrient density to increase physiological imbalance at different stages of lactation. J Dairy Sci 95: 2362-2380

Bossaert P, Leroy MR, De Vliegher S, Opsomer G 2008: Interrelations between glucose-induced insulin response, metabolic indicators, and time of first ovulation in high-yielding dairy cows. J Dairy Sci 91: 3363-3371

Chapel JM, Muiño R, Pereira V, Castillo C, Hernández J, Benedito JL 2017: Relationship of BCS prepartum with reproductive performance and lipomobilization in Holstein dairy cows. Pak Vet J 37: 215-219

Cincović M, Kirovski D, Vujanac I, Belić B, Đoković R 2017: Relationship between the indexes of insulin resistance and metabolic status in dairy cows during early lactation. Acta Vet-Beograd 67: 57-70

Cincović MR, Belić B, Đoković R, Toholj B, Hristovska T, Delić B, Došenović M 2014: Insulin resistance in cow during dry period and early lactation. Contemp Agric 63: 98-105

De Koster J, Hostens M, Van Eetvelde M, Hermans K, Moerman S, Bogaert H, Depreester E, Van den Broeck W, Opsomer G 2015: Insulin response of the glucose and fatty acid metabolism in dry dairy cows across a range of body condition scores. J Dairy Sci 98: 4580-4592

De Koster JD, Opsomer G 2013: Insulin resistance in dairy cows. Vet Clin North Am Food Anim Pract 29: 299-322

Duehlmeier R, Sammet K, Widdel A, von Engelhardt W, Wernery U, Kinne J, Sallmann HP 2007: Distribution patterns of the glucose transporters GLUT4 and GLUT1 in skeletal muscles of rats (Rattus norvegicus), pigs (Sus scrofa), cows (Bos taurus), adult goats, goat kids (Capra hircus), and camels (Camelus dromedarius). Comp Biochem Physiol 146: 274-282

Grummer RR 2008: Nutritional and management strategies for the prevention of fatty liver in dairy cattle. Vet $\mathrm{J}$ 176: $10-20$

Hayirli A 2006: The role of exogenous insulin in the complex of hepatic lipidosis and ketosis associated with insulin resistance phenomenon in postpartum dairy cattle. Vet Res Comm 30: 749-774

Holtenius P, Holtenius K 2007: A model to estimate insulin sensitivity in dairy cows. Acta Vet Scand 49: 29-31

Holtenius K, Agenas S, Delavaud C, Chilliard Y 2003: Effects of feeding intensity during the dry period. 2. Metabolic and hormonal responses. J Dairy Sci 86: 883-891

Janovick NA, Drackley JK 2010: Prepartum dietary management of energy intake affects postpartum intake and lactation performance by primiparous and multiparous Holstein cows. J Dairy Sci 93: 3086-3102

Locher L, Häussler S, Laubenthal L, Singh SP, Winkler J, Kinoshita A, Kenéz A, Rehage J, Huber K, Sauerwein H, Dänicke S 2015: Effect of increasing body condition on key regulators of fat metabolism in subcutaneous adipose tissue depot and circulation of nonlactating dairy cows. J Dairy Sci 98: 1057-1068

Marett LC, Auldist MJ, Wales WJ, Macmillan KL, Dunshea FR, Leury BJ 2017: Responses of plasma glucose 
and nonesterified fatty acids to intravenous insulin tolerance tests in dairy cows during a 670-day lactation. J Dairy Sci 100: 3272-3281

Maedler K, Spinas GA, Dyntar D, Moritz W, Kaiser N, Donath MY 2001: Distinct effects of saturated and monounsaturated fatty acids on $\beta$-cell turnover and function. Diabetes 50: 69-76

Perseghin G, Caumo A, Caloni M, Testolin G, Lutz L 2001: Incorporation of the fasting plasma FFA concentration into QUICKI improves its association with insulin sensitivity in non-obese individuals. J Clin Endocrinol Metab 86: 4776-4781

Pires JAA, Pescara JB, Grummer RR 2007: Reduction of plasma NEFA concentration by nicotinic acid enhances the response to insulin in feed-restricted Holstein cows. J Dairy Sci 90: 4635-4642

Rukkwamsuk T, Wensing T, Geelen MJ 1998: Effect of overfeeding during the dry period on regulation of adipose tissue metabolism in dairy cows during the periparturient period. J Dairy Sci 81: 2904-2911

Salin S, Taponen J, Elo K, Simpura I, Vanhatalo A, Boston R, Kokkonen T 2012: Effects of abomasal infusion of tallow or camelina oil on responses to glucose and insulin in dairy cows during late pregnancy. J Dairy Sci 95: $3812-3825$

Salin S, Vanhatalo A, Elo K, Taponen J, Boston RC, Kokonen T 2017: Effects of dietary energy allowance and decline in dry matter intake during the dry period on responses to glucose and insulin in transition dairy cows. J Dairy Sci 100: 5266-5280

Šamanc H, Gvozdić D, Fratrić N, Kirovski D, Djoković R, Sladojević Ž, Cincović M 2015: Body condition score loss, hepatic lipidosis and selected blood metabolites in Holstein cows during transition period. Anim Sci Pap Rep 33: $1-13$

Schoenberg KM, Ehrhardt RM, Overton TR 2012: Effects of plane of nutrition and feed deprivation on insulin responses in dairy cattle during late gestation. J Dairy Sci 95: 670-682

Schoenberg KM, Overton TR 2011: Effects of plane of nutrition and 2,4-thiazolidinedione on insulin responses and adipose tissue gene expression in dairy cattle during late gestation. J Dairy Sci 94: 6021-6035

Vailati-Riboni M, Farina G, Batistel F, Heiser A, Mitchell MD, Crookenden MA, Walker CG, Kay JK, Meier A, Roche JR, Loor JJ 2017: Far-off and close-up dry matter intake modulate indicators of immunometabolic adaptations to lactation in subcutaneous adipose tissue of pasture-based transition dairy cows. J Dairy Sci 100: 2334-2350

Zhao FQ, Keating AF 2007: Expression and regulation of glucose transporters in the bovine mammary gland. J Dairy Sci 90: 76-86 